\title{
Formation of gas-phase carbonyls from heterogeneous oxidation of polyunsaturated fatty acids at the air-water interface and of the sea surface microlayer
}

\author{
S. Zhou ${ }^{1}$, L. Gonzalez ${ }^{2}$, A. Leithead ${ }^{3}$, Z. Finewax ${ }^{1}$, R. Thalman ${ }^{2}$, A. Vlasenko ${ }^{3}$, S. Vagle ${ }^{4}$, L.A. Miller ${ }^{4}$, S.-M. Li $^{3}$, \\ S. Bureekul ${ }^{5}$, H. Furutani ${ }^{5}$, M. Uematsu ${ }^{5}$, R. Volkamer $^{2}$, and J. Abbatt ${ }^{1}$ \\ ${ }^{1}$ Department of Chemistry, University of Toronto, Toronto, Canada \\ ${ }^{2}$ Department of Chemistry and Biochemistry and CIRES, University of Colorado, Boulder, Colorado, USA \\ ${ }^{3}$ Air Quality Research Division, Atmospheric Science and Technology Directorate, Science and Technology Branch, \\ Environment Canada, Canada \\ ${ }^{4}$ Institute of Ocean Sciences, Fisheries and Oceans Canada, Sidney, British Columbia, Canada \\ ${ }^{5}$ Atmosphere and Ocean Research Institute, University of Tokyo, Chiba, Japan \\ Correspondence to: S. Zhou (szhou@chem.utoronto.ca)
}

Received: 12 June 2013 - Published in Atmos. Chem. Phys. Discuss.: 3 July 2013

Revised: 31 October 2013 - Accepted: 11 November 2013 - Published: 5 February 2014

\begin{abstract}
Motivated by the potential for reactive heterogeneous chemistry occurring at the ocean surface, gas-phase products were observed when a reactive sea surface microlayer (SML) component, i.e. the polyunsaturated fatty acids (PUFA) linoleic acid (LA), was exposed to gas-phase ozone at the air-seawater interface. Similar oxidation experiments were conducted with SML samples collected from two different oceanic locations, in the eastern equatorial Pacific Ocean and from the west coast of Canada. Online proton-transferreaction mass spectrometry (PTR-MS) University of Colorado light-emitting diode cavity-enhanced differential optical absorption spectroscopy (LED-CE-DOAS) were used to detect oxygenated gas-phase products from the ozonolysis reactions. The LA studies indicate that oxidation of a PUFA monolayer on seawater gives rise to prompt and efficient formation of gas-phase aldehydes. The products are formed via the decomposition of primary ozonides which form upon the initial reaction of ozone with the carbon-carbon double bonds in the PUFA molecules. In addition, two highly reactive dicarbonyls, malondialdehyde (MDA) and glyoxal, were also generated, likely as secondary products. Specific yields relative to reactant loss were $78 \%, 29 \%, 4 \%$ and $<1 \%$ for $n$-hexanal, 3-nonenal, MDA and glyoxal, respectively, where the yields for MDA and glyoxal are likely lower limits. Heterogeneous oxidation of SML samples confirm for the first
\end{abstract}

time that similar carbonyl products are formed via ozonolysis of environmental samples.

\section{Introduction}

The ocean covers more than $70 \%$ of the Earth's surface, and the sea surface microlayer (SML) is an important boundary which plays a crucial role in chemical exchange between the atmosphere and ocean (Donaldson and George, 2012). Recent field observations indicate missing sources for oxygenated hydrocarbons from the oceans in atmospheric models (Myriokefalitakis et al., 2008; Sinreich et al., 2010). It is known that the SML is a complex organic and inorganic mixture (Pogorzelski and Kogut, 2003; Kozarac et al., 2005). The organic substances in the SML, including proteins, polysaccharides, humic-type materials and lipids, are likely produced from marine biota (Wilson and Collier, 1972; Gašparovic et al., 1998). As a main component of lipids, fatty acids (FA), including polyunsaturated FA (PUFA) have been detected in considerable amounts in sea surface water with concentrations of 3-200 $\mathrm{g} \mathrm{L} \mathrm{L}^{-1}$ (Marty et al., 1979; Derieux et al., 1998; André et al., 2004; Parrish et al., 2005; Blaženka et al., 2007). PUFA contribute as much as $\sim 43 \%$ of the total FA measured, for example, in sub-Arctic Norwegian fjords 
(Blaženka et al., 2007). In addition, PUFA have also been detected in marine aerosols (Kawamura and Gagosian, 1987; Mochida et al., 2002; Fang et al., 2002).

As surfactants with carbon-carbon double bonds, PUFA reside at the air/water interface and provide information on the degradation state of the organic matter in the SML and aerosols (Blanchard, 1964; Barger and Garrett, 1970, 1976; Donaldson and Vaida, 2006). Despite their environmental prevalence the atmospheric importance of PUFA remains poorly characterized. In particular, as a significant component of the SML, are these species reactive with atmospheric oxidants when present on the water surface? As a result of oxidation, what species are formed and are the products readily released to the atmosphere?

To date, the focus of laboratory studies in this area has been on the kinetics of heterogeneous oxidation of pure unsaturated FA compounds, especially on oleic acid (OA) (Zahardis and Petrucci, 2007). Besides studies on pure FA liquids and aerosols which indicate reactive uptake coefficients on the order of $10^{-3}$, notable studies include those of McNeil et al. (2007), who reported an uptake coefficient of roughly $10^{-5}$ for ozone on oleate-aqueous salt aerosols and González-Lebrada et al. (2007), who measured $10^{-6}$ for monolayer OA on aqueous droplets. These values are comparable with the initial uptake coefficients for ozone on terminal alkenes on self-assembled monolayer (Dubowski et al., 2004). Based on additional measurements involving the $\mathrm{OH}$ and $\mathrm{NO}_{3}$ oxidants on oleate-aqueous salt particles by McNeil et al. (2007), the lifetime of unsaturated organics at the air-water interface can be estimated to be $\sim 10$ min with respect to reaction with atmospheric levels of ozone $(50 \mathrm{ppb})$, whereas the lifetimes with respect to $\mathrm{OH}$ reaction would be significantly longer (McNeil et al., 2007; González-Lebrada et al., 2007). Kinetics studies with PUFA such as linoleic acid (LA) and linolenic acid yield comparable results to those with OA (Moise and Rudich, 2002; Thornberry and Abbatt, 2004; Zhao et al., 2011).

Moreover, gas-phase aldehyde formation has been widely reported from studies with pure substrates (Zahardis and Petrucci, 2007, references therein). Among them, Moise and Rudich (2002) first quantified a yield of gas-phase nonanal as $28 \%$ from $\mathrm{O}_{3}+\mathrm{OA}$ at room temperature, and $\sim 50 \%$ yields were reported by Thornberry and Abbatt (2004) and Vesna et al. (2009). Thornberry and Abbatt (2004) also reported $n$ hexanal and nonenal yields of $\sim 25 \%$ for the ozone reaction with LA thin film, suggesting that the two LA carbon-carbon double bonds have the same probability to be attacked by ozone.

In addition to gas-phase aldehydes, several lower-volatility products, namely azelaic acid, nonanoic acid and 9oxononanoic acid, have been quantified from ozonolysis of pure OA, with 9-oxononanoic acid the most prevalent with yields of 14-35\% (Katrib et al., 2004; Hung et al., 2005; Ziemann, 2005), while azelaic and nonanoic acid yields are less than $10 \%$ (Katrib et al., 2004; Ziemann, 2005). It is notable that these yields are different from King et al. (2009), who reported $87 \%$ for nonanoic acid from heterogeneous ozonolysis of a monolayer of deuterated OA on water. This latter result implies that the heterogeneous ozonolysis mechanism may be different for an FA monolayer at the air-water interface than for a pure substance.

The goals of this work are threefold. First, given the dominance of product studies performed with pure substances, there is the need to determine the gas-phase products that form from heterogeneous oxidation of PUFA when present as a monolayer on an aqueous substrate, to better match conditions at the air-seawater interface in the marine boundary layer (MBL). Of particular interest is whether soluble species are promptly released to the gas phase or whether they dissolve instead in the underlying aqueous medium. Measurements are performed with LA monolayers sitting on seawater in a flow tube coupled to online proton transfer reaction mass spectrometers (PTR-MS) and a light-emitting diode cavityenhanced differential optical absorption spectrometer (LEDCE-DOAS). Second, we investigate whether or not highly reactive dicarbonyls can be formed from this heterogeneous reaction. Finally, we investigate whether similar oxygenated volatile organic carbons (VOCs), especially carbonyls, form when natural SML samples are exposed to ozone. To the best of our knowledge, this is the first study of the heterogeneous oxidation of natural SML materials.

\section{Experimental}

\subsection{Flow tube apparatus and detection schemes}

Heterogeneous ozonolysis of LA on seawater was performed at room temperature $(296 \pm 3 \mathrm{~K})$ in a flow tube apparatus shown in Fig. 1. A LA monolayer was prepared by adding either $2 \mu \mathrm{L}$ of pure LA ( $\geq 99 \%$, Sigma-Aldrich) (Type 1 experiments) or $2-4 \mu \mathrm{L}$ of a LA-dichloromethane (DCM, HPLC grade, $\geq 99.9 \%)$ solution $\left(1.6 \times 10^{-2} \mathrm{M}\right)$ (Type 2 experiments) onto $10 \mathrm{~mL}$ commercial seawater (Sigma-Aldrich) which had been added into a glass boat $(2 \mathrm{~cm}$ wide and $20 \mathrm{~cm}$ long) prior to addition of LA. The glass boat was placed inside a $2.2 \mathrm{~cm}$ i.d., $50 \mathrm{~cm}$ long glass flow tube with two inlets. In Type 1 experiments, an oily drop of LA can be visually seen after the pure LA was added on the seawater, while it was not observed in the Type 2 experiments, where the DCM was evaporated by passing clean air through the flow tube for 15 min after LA-DCM solution was added onto the seawater. Ozone was introduced into the flow tube from one inlet and the flow tube outlet was connected to the analytical instruments (Fig. 1a). The relative humidity at the exit of the flow tube was $\sim 40 \%$.

Ozone was generated by passing $1000 \mathrm{sccm}$ of synthetic air through an ozone generator that was composed of a quartz cell and a Pen-Ray lamp with a metal cover, which regulated the ozone formation rate. The ozone mixing ratio was 

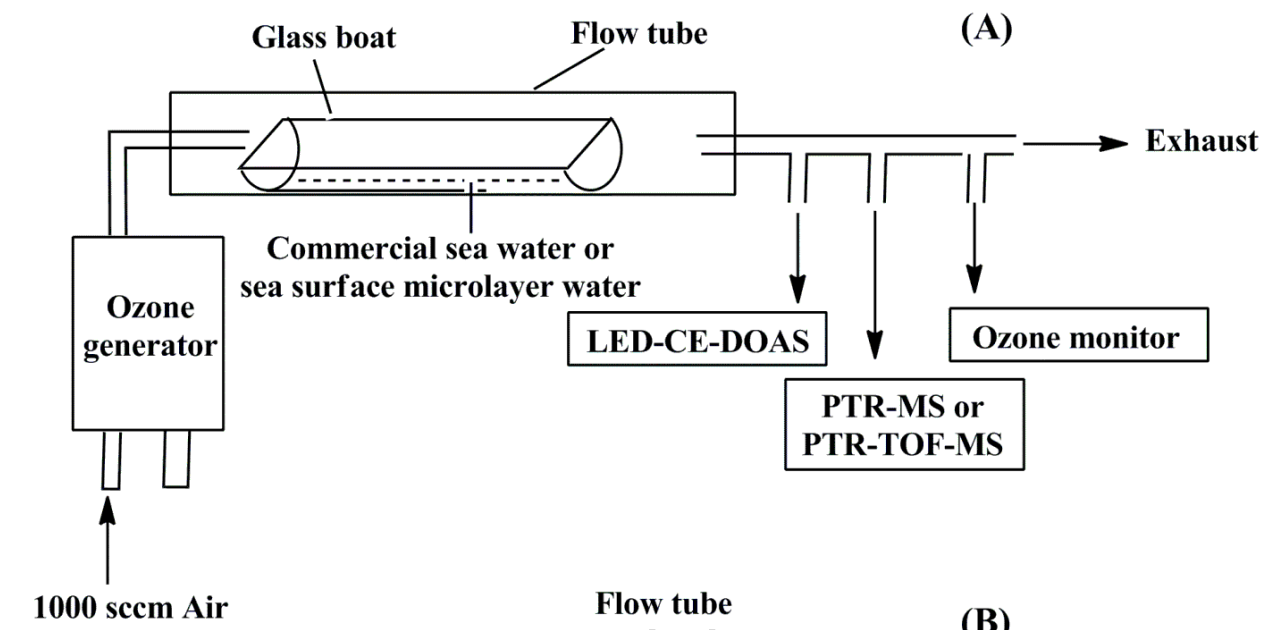

Flow tube or chamber

(B)

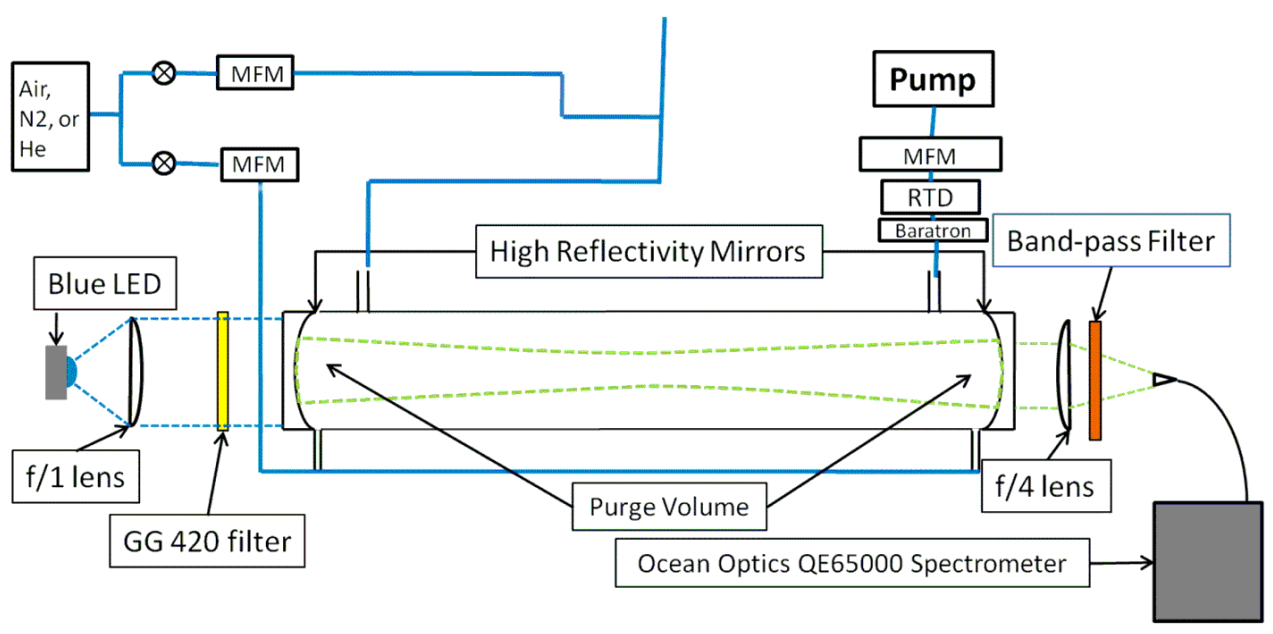

Fig. 1. Schematic of the flow tube apparatus (A) and LED-CE-DOAS instrument (B).

measured by a UV photometric $\mathrm{O}_{3}$ analyzer (Thermo Model $49 i$ ) and by the LED-CE-DOAS. A unit resolution PTRMS (Ionicon Analytik GmbH) and an LED-CE-DOAS instrument were placed downstream of the flow tube to detect the gas-phase products, with $100 \mathrm{sccm}$ going to the PTR-MS and $500 \mathrm{sccm}$ to the LED-CE-DOAS. The residence time for ozone as well as gas-phase products in the flow tube is $\sim 10 \mathrm{~s}$.

The proton transfer reaction mass spectrometry (PTRMS) has been described in detail by de Gouw and Warneke (2007). Briefly, the instrument utilizes a soft chemical ionization technique, transferring $\mathrm{H}^{+}$from the reagent ion, $\mathrm{H}_{3} \mathrm{O}^{+}$, to gas-phase species with a higher proton affinity than water. Here, the PTR-MS was run under either scan mode, in which the PTR-MS recorded multiplier signal in the $m / z$ range of 21 to 150 , or selected ion mode (SIM), in which only the signals from the masses of interest were recorded.

For the SML and some LA studies, a PTR-TOF-MS with a time-of-flight mass spectrometer was used along with a switchable reagent ion source (SRI, including $\mathrm{H}_{3} \mathrm{O}^{+}$and $\mathrm{NO}^{+}$) (Jordan et al., 2009). The SRI enables identification of VOC isomers indistinguishable with $\mathrm{H}_{3} \mathrm{O}^{+}$ionization, e.g. aldehyde and ketone isomers (Dunne et al., 2012). In this work, $\mathrm{NO}^{+}$was used to differentiate aldehyde and ketone isomers, because $\mathrm{NO}^{+}$reacts with aldehydes to produce mainly dehydrogenated cations $(\mathrm{M}-\mathrm{H})^{+}$, whereas its reaction with ketones yields $\mathrm{NO}^{+}$cluster ions $(\mathrm{M}+\mathrm{NO})^{+}(\mathrm{Jor}-$ dan et al., 2009).

The University of Colorado LED-CE-DOAS instrument (Thalman and Volkamer, 2010) employs a blue LED light source (420-490 nm) coupled to a high finesse optical cavity consisting of two highly reflective mirrors $(R=0.99997)$ placed about $92 \mathrm{~cm}$ apart, leading to a wavelength-dependent sampling path length of $\sim 18 \mathrm{~km}$. The mirrors are purged with dry nitrogen gas, and the mirror reflectivity was determined by flowing helium and nitrogen gas; the mirror alignment is further monitored online by observing the slant column density of oxygen dimers $\left(\mathrm{O}_{4}\right)$. The light exiting the cavity is projected onto a quartz optical fiber coupled to an Ocean Optics QE65000 spectrometer equipped with a CCD detector. The spectra recorded are stored on a computer and 
analyzed by means of DOAS least squares fitting. The measured concentrations are calibrated from knowledge of reference spectra of glyoxal (Volkamer et al., 2005a), nitrogen dioxide (Vandaele et al., 2002), ozone (Bogumil, 2003) and oxygen dimmers (Hermans, 1999). The concentration for ozone was retrieved using an absolute intensity fitting procedure (Washenfelder et al., 2008) as the dominant absorption of ozone at these wavelengths is mostly broadband. Detection limits for glyoxal, $\mathrm{NO}_{2}, \mathrm{O}_{4}$, and ozone were $20 \mathrm{pptv}$, 25 pptv, $0.01 \%$ mixing ratio, and $30 \mathrm{ppbv}$ respectively (Thalman and Volkamer, 2010).

To quantify the gas-phase products, the PTR-MS was calibrated with four aldehydes, namely propanal, 3-hexenal, $n$ hexanal and 2-nonenal, which was used as a surrogate for 3-nonenal, which was commercially unavailable. The calibration was performed by introducing a known amount of either pure liquid sample or $n$-heptane solutions into a $1 \mathrm{~m}^{3}$ Teflon chamber. $n$-heptane was used as a solvent to dissolve the aldehydes because it had minimum interference with the selected $\mathrm{m} / z$ signals for the above-mentioned aldehydes. In addition, the $n$-hexanal PTR-MS calibration from the chamber was verified by introducing a known pressure of $n$-hexanal into an evacuated $3 \mathrm{~L}$ glass reservoir, which was then diluted with nitrogen. The $n$-hexanal PTR-MS signal was calibrated using flow tube mixing ratios calculated from the pressure drop with time of the glass reservoir, as the flow was metered out through a needle value. The PTR-TOF-MS was calibrated by diluting ppm level gas standards from a gas cylinder containing acetaldehyde, acrolein, acetone and 2-butanone (Ionimed Analytik GMBH).

Using the apparatus in Fig. 1 and the PTR-TOF-MS with $\mathrm{H}_{3} \mathrm{O}^{+}$as reagent ion, gas-phase products from the heterogeneous reaction of ozone, generated by passing $500 \mathrm{sccm}$ of synthetic air through the ozone generator, with SML samples were investigated. The SML samples were collected in two locations, one from Patricia Bay, Canada (SML-CA), and the other from the eastern equatorial Pacific Ocean (SMLEqPOS). Detailed information about the SML sample collection is given in the Supplement. After the SML samples were collected they were transported in dry ice and kept frozen in the laboratory at $-18^{\circ} \mathrm{C}$. The SML samples thawed at room temperature and $10 \mathrm{~mL}$ were added into the glass boat inside the flow tube. Control experiments were conducted in a manner analogous to the oxidation experiment without the SML sample present.

\subsection{Chamber experiments}

As will be shown later, malondialdehyde (MDA) and glyoxal were observed as products from ozonolysis of LA. The formation of MDA and glyoxal is mostly attributed to a secondgeneration product from reaction of 3-nonenal with ozone. To prove this hypothesis, the gas-phase reaction of ozone with 3-hexenal, used as a surrogate for commercially unavailable 3-nonenal, was conducted in the $1 \mathrm{~m}^{3}$ Teflon chamber.
The chamber was made of PFA (perfluoroalkoxy) Teflon film with a Teflon-tape-wrapped metal frame inside to support the bag. The chamber was flushed overnight by purified air before starting the experiment. Approximately $200 \mathrm{ppb}$ cis-3hexenal (50\% in triacetin, Sigma-Aldrich) and $\sim 200 \mathrm{ppm}$ cyclohexane (HPLC grade, $\geq 99.9 \%$ ) were added into the chamber before $\sim 300 \mathrm{ppb}$ ozone was introduced. Cyclohexane was present in excess to scavenge more than $95 \%$ of $\mathrm{OH}$ radicals produced in the reaction. The reactants and products were detected by the PTR-MS and LED-CE-DOAS.

\section{Results and discussion}

\subsection{LA monolayers on seawater}

In the Type 1 experiments, it is expected that the drop of LA will spread to produce a monolayer over the seawater surface. To test this, a control experiment was conducted by adding $2 \mu \mathrm{L}$ pure LA into a clean glass boat without seawater and passing ozone through the flow tube at the same levels as used in the oxidation experiments.

The product signals recorded by the PTR-MS for the control were more than an order of magnitude lower than those for the Type 1 experiments, confirming that the LA does spread across the seawater surface but does not spread over a dry glass boat.

Indeed, Rouviére and Ammann (2010) investigated the monolayer properties of fatty acids coated on deliquesced KI particles and reported that, if more than a monolayer is deposited, the fatty acid formed a monolayer and the residual remained as an excess droplet in contact with the aqueous solution. It is expected that this is the case for the Type 1 experiments in this work.

\subsection{Identification of gas-phase aldehydes from ozonolysis of monolayer LA}

Figure 2 shows a typical mass spectrum for the gas-phase products from Type 1 experiments recorded by the PTRMS under scan mode (a) and the evolution of selected ions recorded by PTR-TOF-MS (b). Based on previous studies (Moise and Rudich, 2002; Thornberry and Abbatt, 2004) $\mathrm{m} / \mathrm{z} 141$ and 123 in Fig. 2a and $141.13\left(\mathrm{C}_{9} \mathrm{H}_{17} \mathrm{O}^{+}\right)$and $123.12\left(\mathrm{C}_{9} \mathrm{H}_{15}^{+}\right)$in Fig. $2 \mathrm{~b}$ were identified as protonated 3-nonenal $(\mathrm{M}+1)$ and its dehydrated ions $(\mathrm{M}-18+1)$, respectively. $m / z 101$ and 83 in Fig. 2a and $m / z 101.10$ $\left(\mathrm{C}_{6} \mathrm{H}_{13} \mathrm{O}^{+}\right)$and $83.08\left(\mathrm{C}_{6} \mathrm{H}_{11}^{+}\right)$in Fig. $2 \mathrm{~b}$ are attributed to protonated $n$-hexanal $(\mathrm{M}+1)$ and its dehydrated ions (M$18+1$ ), respectively. The signals at $m / z 123$ and 83 from PTR-MS were used to quantify 3-nonenal and $n$-hexanal, respectively. Other $m / z$ in Fig. 2 were from further decomposition of protonated or dehydrated 3-nonenal and $n$-hexanal, with exception of the signal at $m / z 73$ in Fig. 2a.

Several aldehyde and ketone isomers - e.g. butanal, butanone, methyl glyoxal or MDA - have the same nominal unit 

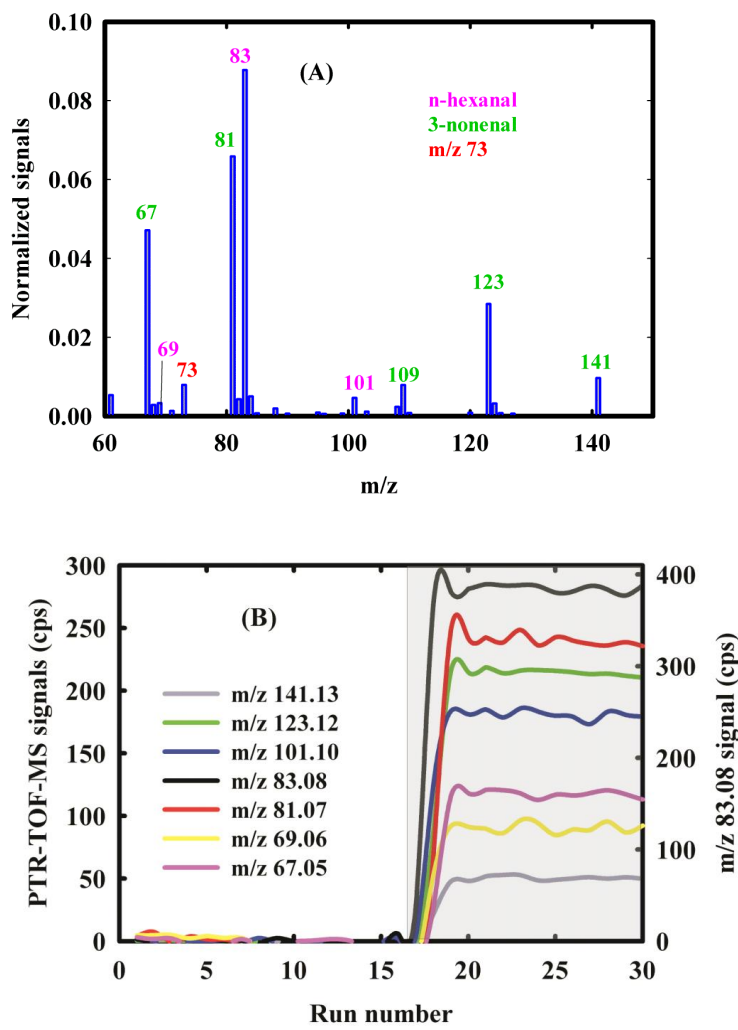

Fig. 2. Mass spectra for the gas-phase products from Type 1 experiments recorded by PTR-MS (A) and PTR-TOF-MS (B). In (B), the shaded area represents exposure to $500 \mathrm{ppb} \mathrm{O}_{3}$.

mass molecular weight and may produce protonated molecular ions at $m / z 73$ in the PTR-MS. Therefore, absolute identification of this product with PTR-MS alone is impossible. However, Fig. 3a gives the PTR-TOF-MS mass spectrum of this product with $\mathrm{H}_{3} \mathrm{O}^{+}$as reagent ion, showing the exact mass to be $73.02(\mathrm{M}+1)$, suggesting its molecular formula is $\mathrm{C}_{3} \mathrm{H}_{4} \mathrm{O}_{2}$ (note the different scales in Fig. 3a with ozone off and on). Therefore, the monocarbonyls, butanal and butanone $\left(\mathrm{C}_{4} \mathrm{H}_{8} \mathrm{O}\right)$, can be excluded from the candidate products. In Fig. $3 b$ the reagent ion is switched from $\mathrm{H}_{3} \mathrm{O}^{+}$to $\mathrm{NO}^{+}$just after run 30. The $m / z 73.02\left(\mathrm{C}_{3} \mathrm{H}_{5} \mathrm{O}_{2}^{+}\right)$signal was highest with $\mathrm{H}_{3} \mathrm{O}^{+}$as the reagent ion, with the signal dropping to background level with $\mathrm{NO}^{+}$. Concurrently, the signal at $m / z 71.01\left(\mathrm{C}_{3} \mathrm{H}_{3} \mathrm{O}_{2}+\right)$ rises, indicating $\mathrm{H}$-atom abstraction from the molecular ion $\mathrm{C}_{3} \mathrm{H}_{4} \mathrm{O}_{2}$, while signal at $m / z 102.02\left(\mathrm{C}_{3} \mathrm{H}_{4} \mathrm{O}_{2} \mathrm{NO}^{+}\right)$remains unchanged. This is consistent with the accepted mechanism by which $\mathrm{NO}^{+}$reagent ions react with aldehydes. Note that methyl glyoxal can be ruled out as a candidate because a sample of this gas behaves differently with the $\mathrm{NO}^{+}$reagent ion (Fig. S1) than the behavior displayed in the experiment; i.e. the $\mathrm{m} / \mathrm{z} 102.02$ $\left(\mathrm{C}_{3} \mathrm{H}_{4} \mathrm{O}_{2} \mathrm{NO}^{+}\right)$signal rises substantially when the reagent ion is switched from $\mathrm{H}_{3} \mathrm{O}^{+}$to $\mathrm{NO}^{+}$. Hence, in combination
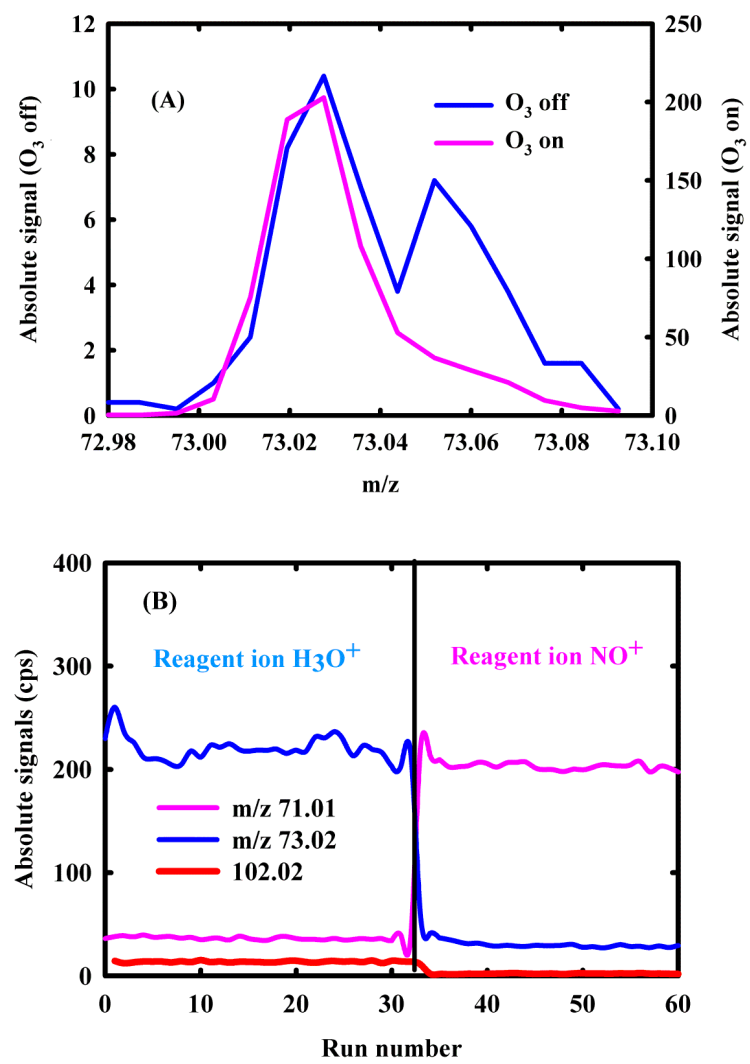

Fig. 3. PTR-TOF-MS mass spectrum of the signal at $\mathrm{m} / \mathrm{z} 73.02$ recorded with $\mathrm{H}_{3} \mathrm{O}^{+}$as the reagent ion (A) and three signals recorded with PTR-TOF-MS as the reagent ion is switched from $\mathrm{H}_{3} \mathrm{O}^{+}$to $\mathrm{NO}^{+}(\mathbf{B})$ from Type 1 experiment with $500 \mathrm{ppb} \mathrm{O}_{3}$ exposure.

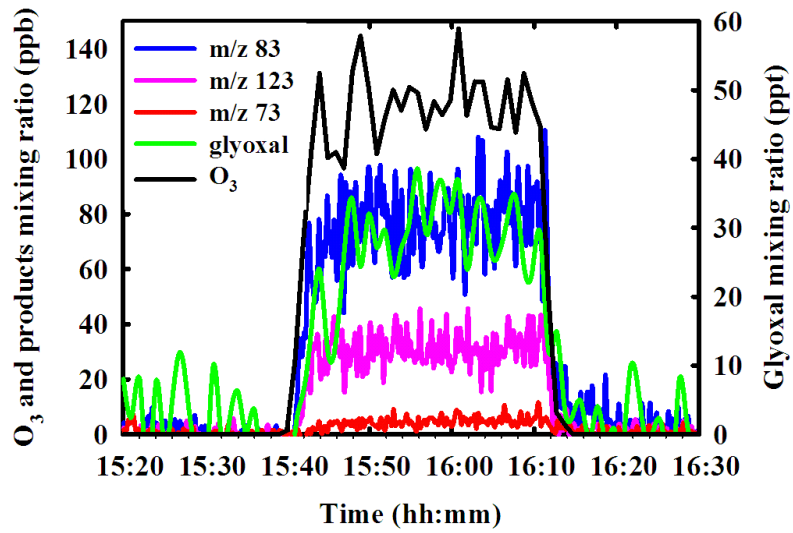

Fig. 4. Example of ozone and product profiles for a Type 1 LA experiment.

with the mechanistic study to be described later, this product is attributed to MDA.

Finally, coincident with the products that are detected by PTR-MS, we note that glyoxal was observed to be formed simultaneously using the LED-CE-DOAS (Fig. 4). 


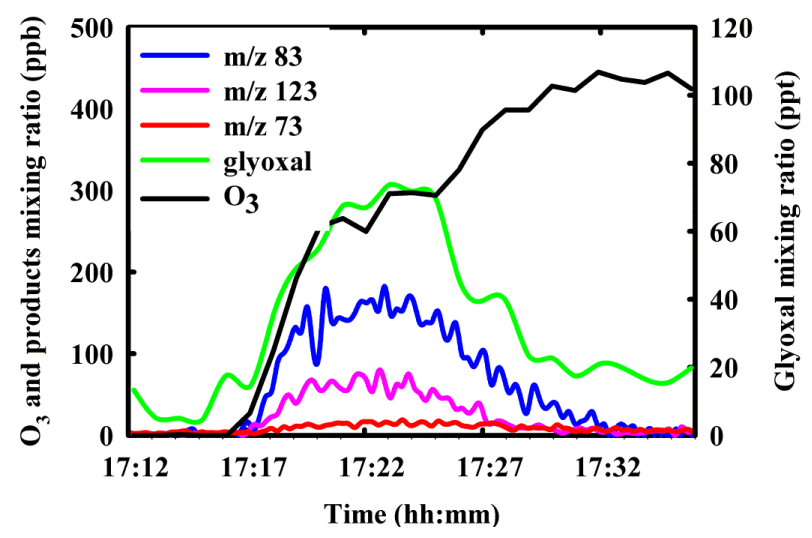

Fig. 5. Example of ozone and product profiles for a Type 2 LA experiment.

As mentioned in the Introduction, the 3-nonenal and $n$ hexanal products have been identified in previous studies (Moise and Rudich, 2002; Thornberry and Abbatt, 2004) on the heterogeneous oxidation of pure LA thin film/particles by ozone. The present work demonstrates that the same products are formed when monolayer LA is oxidized on seawater. However, the formation of two gas-phase dialdehydes, namely MDA and glyoxal, was observed for the first time.

\subsection{Gas-phase aldehyde quantification}

Figures 4 and 5 illustrate the temporal profiles of ozone and gas-phase aldehyde formation from Type 1 and 2 experiments, respectively. Upon ozone exposure, $n$-hexanal $(\mathrm{m} / \mathrm{z}$ 83) and 3-nonenal ( $\mathrm{m} / \mathrm{z}$ 123) formed immediately and quickly reached steady-state levels in Type 1 experiments followed by slightly slower formation of the dicarbonyls, i.e. MDA ( $m / z$ 73) and glyoxal (Fig. 4).

We interpret the steady-state, sustained production of volatile products in Type 1 experiments (Fig. 4) to indicate that the LA monolayer is being replenished by the excess LA droplet. In contrast, the Type 2 experiments, where only $3.8 \times 10^{16}$ molecules (or $1 \times 10^{14}$ molecules $\mathrm{cm}^{-2}$ ) of LA were added to the boat, demonstrate the consumption of the surface coverage. In both cases, we believe that the less volatile reaction products, potentially acids or hydroxyhydroperoxides (Katrib et al., 2004; Hung et al., 2005; Ziemann, 2005), dissolve in the water or remain at the surface. On the one hand, Voss et al. (2007), who investigated the reaction of ozone with $\mathrm{OA}$ monolayer on water, suggested that non-volatile products dissolved into the aqueous phase and did not remain at the interface. In contrast, King et al. (2009) investigated the similar reaction with deuterated $\mathrm{OA}$ at the air/water interface and reported that the nonanoic acid product remained at the surface. This latter scenario seems unlikely in the present work; otherwise the LA monolayer would have been diluted by the condensed-phase products at the interface and the product signals in the Type 1
Table 1. Gas-phase aldehyde formation yields relative to the amount of ozone consumed from Type 1 experiments with LA. The uncertainties reflect the variation in results in 3 experiments, except in the case of glyoxal where the experiment was conducted once.

\begin{tabular}{|c|c|c|c|c|}
\hline \multirow{2}{*}{$\mathrm{O}_{3}$ consumed $(\mathrm{ppb})$} & \multicolumn{4}{|c|}{ Gas-phase aldehyde yields (\%) } \\
\hline & n-hexanal & 3-nonenal & MDA & glyoxal \\
\hline $85-96$ & $78.5 \pm 0.8$ & $30.6 \pm 2.0$ & $1-4$ & $0.03^{\mathrm{a}}(0.1)^{\mathrm{b}}$ \\
\hline $144-150$ & $76.3 \pm 1.6$ & $32.2 \pm 1.5$ & $2-5$ & $0.04^{\mathrm{a}}(0.2)^{\mathrm{b}}$ \\
\hline Average & $77.4 \pm 1.9$ & $31.4 \pm 2.3$ & $1-5$ & $0.03^{\mathrm{a}}(0.15)^{\mathrm{b}}$ \\
\hline
\end{tabular}

Table 2. Gas-phase aldehyde formation yields relative to the amount of LA consumed from Type 2 experiments with LA.

\begin{tabular}{|c|c|c|c|c|}
\hline \multirow{2}{*}{ LA consumed (nmoles) } & \multicolumn{4}{|c|}{ Gas-phase aldehyde yields (\%) } \\
\hline & n-hexanal & 3-nonenal & MDA & glyoxal \\
\hline 32.1 & 78.5 & 24.3 & $2-6$ & $0.06^{\mathrm{a}}(0.20)^{\mathrm{b}}$ \\
\hline 64.2 & 76.7 & 27.1 & $2-7$ & $0.05^{\mathrm{a}}(0.23)^{\mathrm{b}}$ \\
\hline Average & $77.6 \pm 0.9$ & $25.7 \pm 1.4$ & $2-7$ & $0.06^{\mathrm{a}}(0.22)^{\mathrm{b}}$ \\
\hline
\end{tabular}

experiments would have decreased in intensity as the LA oxidation processed.

Tables 1 and 2 summarize the quantification of the gasphase aldehyde yields from Type 1 and 2 experiments, respectively. The product yields in Type 1 experiments were quantified relative to the amount of ozone consumed. In Type 2 experiments, the products were quantified by integrating the individual product peaks in Fig. 5, and the yields are reported relative to the amount of LA consumed on the seawater. The uncertainties in Tables 1 and 2 reflect variability in the experiments. The largest systematic errors in the yields arise from the PTR-MS calibrations which, in combination with other uncertainties, are estimated to be on the order of $\pm 20 \%$. The uncertainty in the glyoxal measurements is estimated to be $\pm 10 \%$. Because the individual yields from the different experiment types are in excellent agreement, we report average yields for $n$-hexanal, 3 -nonenal, and glyoxal of $78 \%, 29 \%$, and $0.04 \%$, respectively.

Given the fact that many research papers report reactive halogen production from the reactions of ozone with aqueous halide solution (Saiz-Lopez and von Glasow, 2012, and references therein), one may inquire whether the ozone reaction with the seawater in this work affected the product yield measurements. To monitor the ozone reaction with the SigmaAldrich seawater, test experiments were conducted using a set-up similar to that for the Type 1 experiments without LA addition. The results show that only $\sim 2 \mathrm{ppb}$ of ozone reacted with the artificial seawater. Compared to the total ozone loss due to reaction with LA in Type 1 experiments (85-150 ppb) 
(Table 1), this loss due to reaction with the seawater is negligible. Therefore, we conclude that, while the contribution of halogen chemistry to aqueous or gas-phase products cannot be ruled out, compared to the ozone reaction its contribution will not affect the product distributions at a significant level. Indeed, we believe that the chemistry would likely occur in an independent manner, with hypohalous acids forming from the reaction of ozone with halides, which will then rapidly form dihalogens that will degas from the solutions.

We note, however, that glyoxal is a highly soluble substance (effective Henry's law constant, $H_{\text {eff }}=4.19 \times 10^{5} \mathrm{M} \mathrm{atm}^{-1}$; Ip et al., 2009) and may dissolve into the condensed phase, while some fraction evaporates to the gas phase. As a result, we can only infer semi-quantitative information about the formation of glyoxal, and the yields reported in Tables 1 and 2 are likely to be lower limits. Given that other gas-phase products account for close to $100 \%$ of the reactants consumed, the glyoxal is not expected to be a major product. Nevertheless, we note that corrected yields for glyoxal in the flow tube experiments could be more than an order of magnitude larger than the yields listed in Tables 1 and 2, if the chemistry at the seawater surface is different from that in the Teflon chamber. In addition, we note that the mechanism by which glyoxal may enter the condensed phase may be affected by the presence of the organic surface layer. In particular, molecular dynamics calculations show that organic monolayers can affect the interactions of molecules like $\mathrm{O}_{3}$ with an aqueous sub-phase. These calculations support that the net-collision rate in the presence of a thin organic layer (butanol, on $\mathrm{NaI}(\mathrm{aq})$ ) is virtually identical to that in the absence of the organic layer (D. Tobias, personal communication, 2013). It is likely that similar trapping applies to other molecules, e.g. glyoxal. However, the limited knowledge of glyoxal uptake and hydration kinetics impedes our full understanding of its loss processes in the flow tube. Nevertheless, given glyoxal's high solubility in water, we believe that the correction factors for glyoxal have the potential to be large.

Preparation of known gas-phase levels of MDA is not easily achieved, and so this signal remains uncalibrated directly. Instead, we estimate the yields of MDA to be $4 \pm 3 \%$ based on the average of the calibration factors for other aldehydes, or using an indirect approach described below. The values plotted in the figures represent those from the indirect approach. However, we note that the same caveat described above for glyoxal also applies for MDA, given that it is expected to be highly soluble; i.e. the yields are expected to be lower limits.

While the 3-nonenal yield is similar to that from the study of the oxidation of pure LA by Thornberry and Abbatt (2004), the $n$-hexanal yield is higher by roughly a factor of 3. As mentioned above, the $n$-hexanal PTR-MS signal was calibrated with two different methods, i.e. using known mixing ratios prepared in a chamber and in the glass bulb/flow tube, and both calibration procedures resulted in similar re- sults. As well, the similarity between the results from the Type 1 and Type 2 experiments suggest there is no error in the amount of reactant consumed. Thus, we conclude that the $n$-hexanal yield from oxidation of LA molecules is different when present as a monolayer on water as compared to the pure form, as studied by Thornberry and Abbatt (2004). The monolayer LA at the air-water interface is likely arranged with the hydrophilic headgroups $(-\mathrm{COOH})$ in direct contact with the aqueous phase and the carbon-carbon double bonds containing hydrophobic tails oriented towards the air (Gill et al., 1983; Ellison et al., 1999; Donaldson and Vaida, 2006). As a result, the $\mathrm{C} 12-\mathrm{C} 13$ carbon-carbon double bond will be farther from the interface and may exhibit less steric hindrance than the $\mathrm{C} 9-\mathrm{C} 10$ bond in reactions with $\mathrm{O}_{3}$ diffusing from the gas phase (Fig. 6). In contrast, when a pure LA liquid is oxidized, the two double bonds in LA may be randomly oriented and exhibit the same collision frequencies with $\mathrm{O}_{3}$.

\subsection{Reaction mechanism for ozonolysis of LA monolayers}

As shown in Fig. 6, the heterogeneous reaction between unsaturated FA and ozone is believed to proceed via addition of ozone to the carbon-carbon double bond forming primary ozonides (PO). The decomposition of the PO leads to aldehydes and the Criegee biradical, which further reacts with water to form acids, hydroxyhydroperoxides, or with carbonyls to form secondary ozonides (Wadia et al., 2000; Moise and Rudich, 2002; Hung and Ariya, 2007; Vesna et al., 2009). The gas-phase product yields indicate that roughly $100 \%$ of the reactants (i.e. either ozone or LA) are converted to the two major products, $n$-hexanal and 3-nonenal. This is in contrast to the results from oxidation of liquid LA by Thornberry and Abbatt (2004), who reported 50\% aldehyde yield. As well, they saw roughly equal yields of $n$-hexanal and 3-nonenal. In the work of Thornberry and Abbatt (2004), the residence time of products and $\mathrm{O}_{3}$ in the flow tube was on the order of $0.1 \mathrm{~s}$, whereas in this work the timescale is $\sim 10 \mathrm{~s}$. Hence, further oxidation of 3-nonenal by ozone may produce $n$-hexanal leading to the higher ratio of $n$-hexanal to 3 -nonenal; i.e. it is possible that both are formed initially at roughly $50 \%$ yield and secondary reactions give rise to the observed enhancement of $n$-hexanal to 3-nonenal. While it is unlikely that the gas-phase kinetics is fast enough to drive this oxidation pathway, it is possible that 3-nonenal is heterogeneously oxidized to $n$-hexanal. While speculative, it is for this reason that we indicate the branching ratios in Fig. 6 to the two primary ozonides to be 50 to $70 \%$ and 30 to $50 \%$.

The roughly $100 \%$ total yield of 3-nonenal and $n$-hexanal suggests that the PO decompose exclusively to gas-phase n-hexanal and 3-nonenal and corresponding Criegee intermediates (CI) that are likely formed on the side of the LA molecule containing a carboxylic acid function group. The fact that the ozonide does not decompose with equal probability into two different sets of aldehydes and $\mathrm{CI}$ is somewhat 


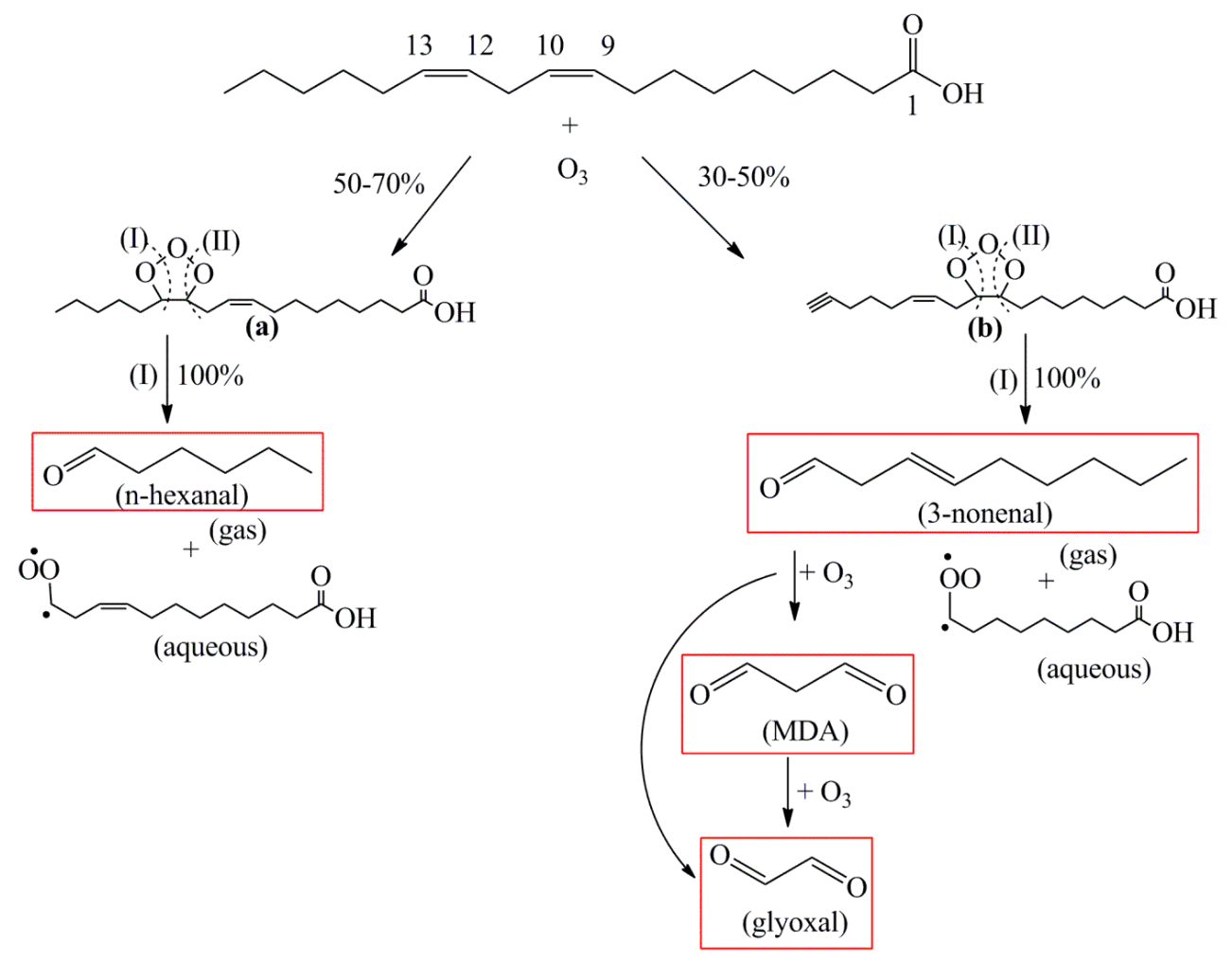

Fig. 6. Reaction mechanism for the heterogeneous reaction of ozone with LA at the air/water interface.

surprising, and it is the reason that we investigated the yields in two different experiments, i.e. the Type 1 and Type 2 experiments, and why we calibrated the PTR-MS to $n$-hexanal via two independent methods. The consistency of the results is excellent. We conclude that the conformation of the LA molecule when existing as a monolayer at the air-water interface preferentially favors decomposition of the ozonide in the manner indicated. While there are a number of studies on the effects of chemical structures on the decomposition pathways of the gas-phase ozonides formed from ozonolysis of alkenes, little is known about the decomposition mechanisms for the ozonides formed from heterogeneous reactions. We can only speculate that perhaps the CI shown to be formed in Fig. 6 might be favored because it has a higher water solubility than the other CI that could form, and perhaps the excited $\mathrm{CI}$ is more easily stabilized by the interaction with liquid water. More experimental and theoretical studies are needed to investigate this mechanism.

This is the first study to probe the reaction mechanism for the heterogeneous reaction of $\mathrm{O}_{3}$ with a PUFA at the air/water interface. As mentioned previously, King et al. (2009) reported a much higher yield of nonanoic acid $(87 \%)$ from heterogeneous reaction of ozone with monolayer deuterated OA at the air/water interface compared to previous studies with pure OA thin films or particles $(\sim 10 \%$; Katrib et al., 2004; Ziemann, 2005); i.e. few volatile aldehydes are expected to have formed in the King et al. (2009) work. By contrast, the work of Wadia et al. (2000) reported a $50 \%$ yield of nonanal from the oxidation of 1-oleoyl2-palmitoyl-sn-glycero-3-phosphocholine sitting at the airwater interface in a compressed state. Interestingly, in one set of experiments from Wadia et al. (2000) using an expanded film of 1-oleoyl-2-palmitoyl-sn-glycero-3-phosphocholine, the yield was two to three times higher than in the compressed state (see Table 2 of Wadia et al., 2000), i.e. matching the $n$-hexanal results from this work where it is likely that the LA films will also be in the expanded state. The present work and these past studies imply that the mechanisms and product yields may be highly dependent on the molecular arrangement for the substrates, and for soluble species also on the effective collision rate with the aqueous sub-phase.

The formation of two dialdehydes, i.e. MDA and glyoxal, may arise from secondary oxidation of 3-nonenal (Fig. 6). To test this reaction mechanism, the gas-phase reaction of ozone with 3-hexenal was investigated in the $1 \mathrm{~m}^{3}$ Teflon chamber, where 3-hexenal was used as a surrogate for 3nonenal, which is commercially unavailable. The experiment was conducted in the presence of $\sim 200 \mathrm{ppm}$ cyclohexane, which was used to scavenge more than $95 \%$ of the $\mathrm{OH}$ radicals generated in the reaction. Fig. 7a shows the time series of the reactant and product mixing ratios, where the signals at $\mathrm{m} / \mathrm{z} 81,59$ and 73 were used to quantify 3 -hexenal, propanal and MDA, respectively. 

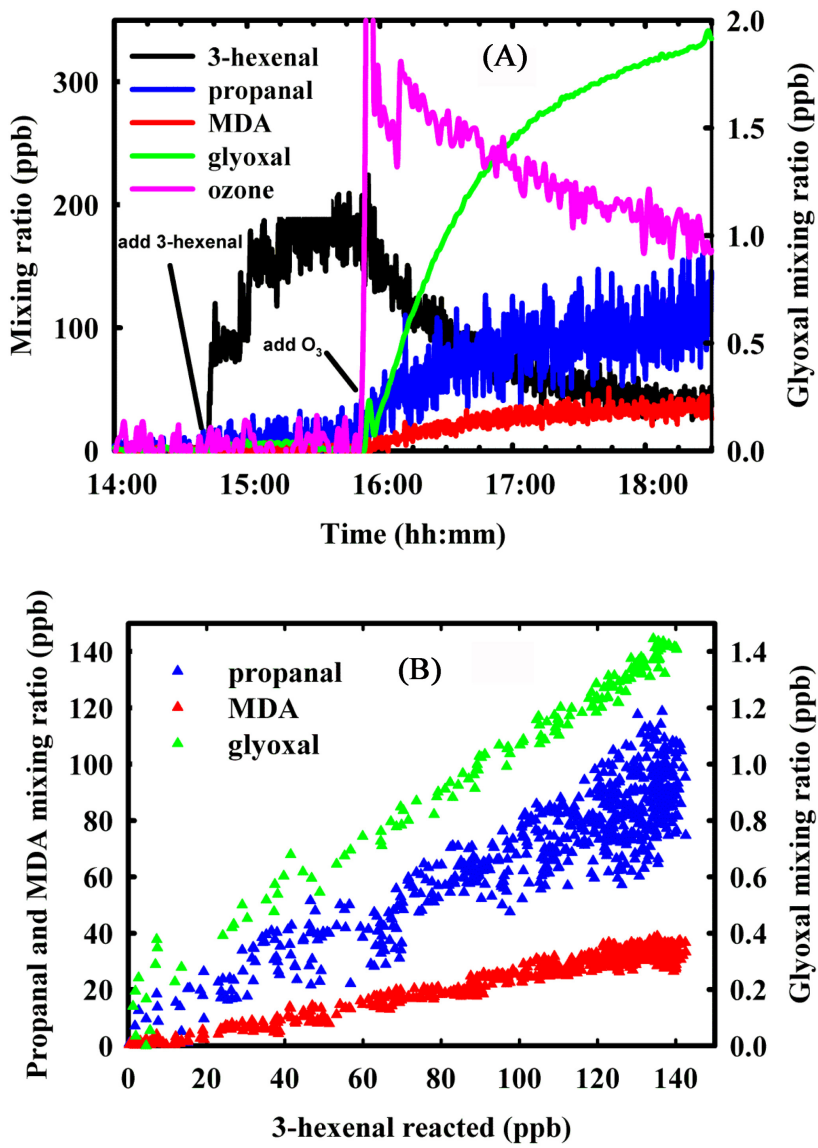

Fig. 7. (A) Time series of the reactants and products and (B) for the reaction of gas-phase 3-hexenal with ozone in the Teflon chamber.

After the signal at $m / z 81$ stabilized, the oxidation of 3hexenal was initiated by addition of ozone, leading to the production of propanal, MDA and glyoxal. The propanal and glyoxal formation yields can be determined from Fig. $7 \mathrm{~b}$ to be $74 \pm 14 \%$ and $0.9 \pm 0.1 \%$, respectively. From the mechanism for the reaction of ozone with 3-hexenal in Fig. 8 it is reasonable to assume the yield of MDA is $25 \pm 5 \%$, which in turn allowed us to indirectly calibrate the $m / z 73$ signal to MDA.

MDA and glyoxal are formed as first-generation oxidation products from ozonolysis of 3-hexenal (Fig. 7). Possible formation mechanisms for MDA and glyoxal are shown in Fig. 8 and rationalize the rapid observed formation of MDA and glyoxal in this system.

A 1,4-H shift of the Criegee biradical can explain the rapid formation of small amounts of glyoxal. 1,4-H shifts have recently been proposed (Dibble et al., 2004a, b) to explain observations of minor products in the oxidation of isoprene (Volkamer et al., 2005b; Paulot et al., 2009; Galloway et al., 2011). The yields of products from 1,4-H shifts are generally small (few percent), consistent with those in this work.
The relative yield of glyoxal / MDA is $\sim 1 / 20$ in the Teflon chamber, while this ratio in the flow tube is 3-5 times smaller. This might be due to the soluble loss of glyoxal in the aqueous sub-phase. If the same relative yields of glyoxal/MDA are assumed from ozonolysis of 3-hexenal and 3 -nonenal, the glyoxal formation yields in the flow tube experiments could be higher (Tables 1 and 2). The factor of 3-5 higher yields after correction are a lower limit for the overall losses that might be occurring in the flow reactor, since MDA concentrations have not been corrected for solubility in the aqueous sub-phase. As such, efficient uptake for glyoxal would indicate that the presence of an organic SML is not an efficient barrier to prevent glyoxal losses to the aqueous sub-phase (see also discussion in the previous section).

In addition, glyoxal may also be produced from interaction of ozone with the enol form of MDA, which has been shown to be stable, both in solution and in the gas phase (Brown et al., 1979; Trivella et al., 2008) (Fig. 8). However, based on the time series of the MDA and glyoxal in Fig. 7 the contribution of further oxidation of MDA to glyxoal formation should be of minor importance.

In one additional Type 1 experiment (see Fig. 9), we passed the effluent from the LA flow tube through a second flow tube in which was placed a $20 \mathrm{~cm}$-long, $254 \mathrm{~nm}$ Hg Pen-Ray lamp (see Lambe et al. (2011) for a description of the flow tube). The combination of water vapor, ozone and UV radiation results in high steady-state $\mathrm{OH}$ concentrations, on the order of $10^{9}$ to $10^{10}$ molecules $\mathrm{cm}^{-3}$, over a residence time of roughly $30 \mathrm{~s}$. When the UV light source was turned on, there were losses in the levels of the $n$-hexanal, 3-nonenal and MDA and pronounced formation of glyoxal. This suggests that these precursors, mostly likely 3-nonenal and MDA, can be oxidized to glyoxal with $\mathrm{OH}$ radicals.

\subsection{Gas-phase products from ozonolysis of natural SML samples}

Similar gas-phase products from heterogeneous ozonolysis of two natural SML samples, SML-CA and SML-EqPOS, were observed by PTR-TOF-MS with $\mathrm{H}_{3} \mathrm{O}^{+}$as reagent ion. Fig. 10 presents the evolution of selected masses during oxidation of SML-CA with ozone. After the samples were added to the glass boat most PTR-TOF-MS signals increased quickly to a maximum and then slowly decreased as the samples degassed. While it is possible that some of these signals arise from species that were originally dissolved in the SML at the point of collection, it is more likely that these species formed after collection via some form of sample degradation. When the signals had almost levelled off, the oxidation of organic substances in the SML was initiated by turning on the ozone generator.

Heterogeneous oxidation of SML samples by ozone produced two sets of products, with one set observed in both the SML-CA and the SML-EqPOS samples (Fig. 10a) and the other observed only in the SML-CA samples (Fig. 10b). 


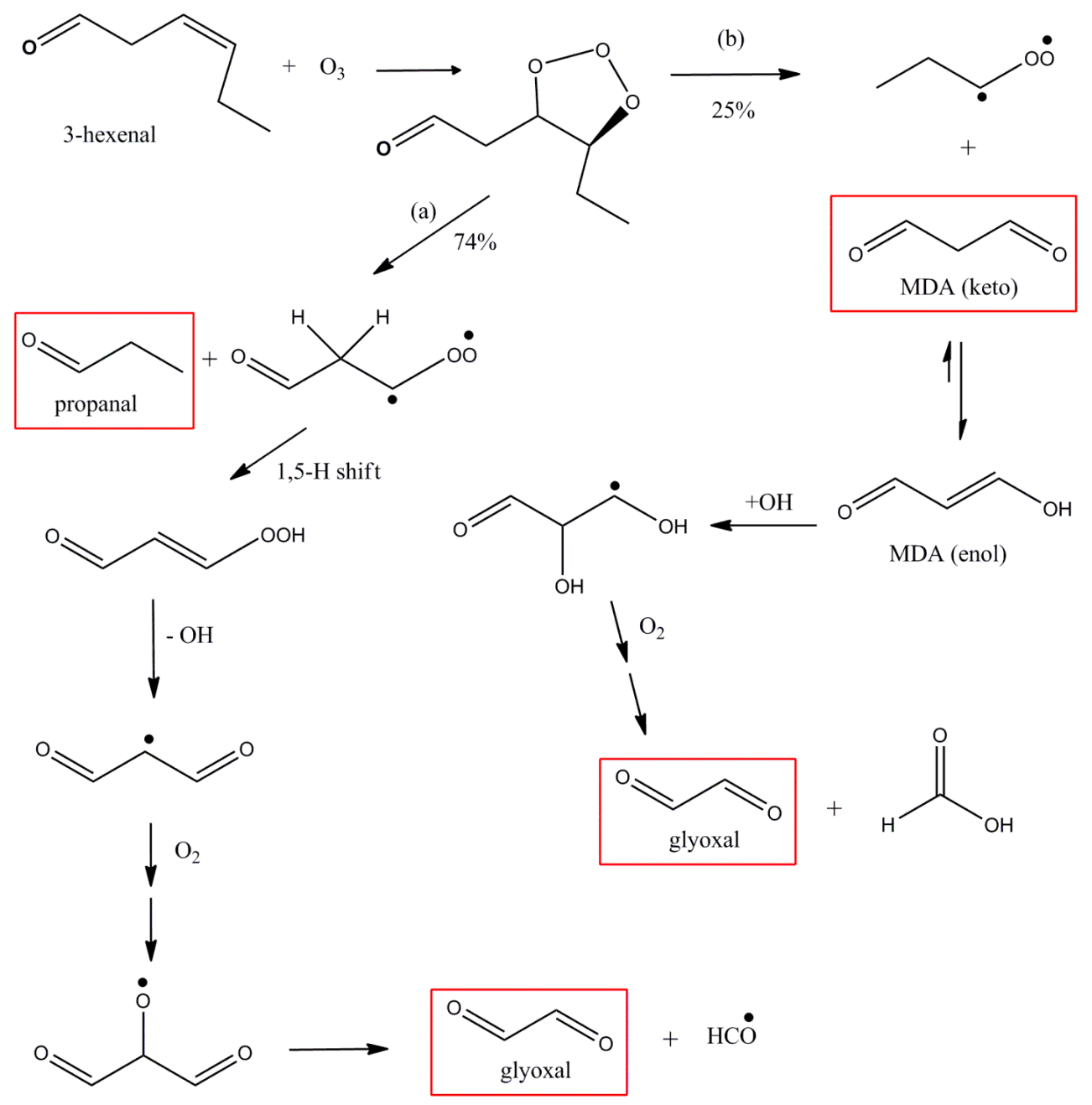

Fig. 8. Reaction mechanism for ozonolysis of cis-3-hexenal and glyoxal formation from MDA oxidation.

Similar to Type 1 experiments, the signals at $m / z$ 45.03, 59.04, 73.02 and 73.06 in Fig. 10a, together with $m / z$ 87.04, 87.07 and 101.02 (not shown), increased and remained steady with each ozone exposure, indicating that their precursors are being replenished after being consumed at the air-water interface. The $m / z$ 45.03, 59.04, 73.06 and 87.07 sequence corresponds to $\mathrm{C}_{2} \mathrm{H}_{5} \mathrm{O}^{+}, \mathrm{C}_{3} \mathrm{H}_{7} \mathrm{O}^{+}, \mathrm{C}_{4} \mathrm{H}_{9} \mathrm{O}^{+}$ and $\mathrm{C}_{5} \mathrm{H}_{11} \mathrm{O}^{+}$, respectively. These species are likely arising from protonated molecular ions of monocarbonyls, i.e. acetaldehyde, propanal/acetone, butanal/butanone and pentanal/pentanone, respectively. Warneke et al. (2003) reported that in C4 and higher aldehyde PTR-MS analysis the dehydrated ions $(\mathrm{M}-18+1)$ dominate over the protonated molecular ions $(\mathrm{M}+1)$, while $\mathrm{C} 3-\mathrm{C} 6$ ketones produced $100 \%$ protonated molecular ions $(\mathrm{M}+1)$. And so, we examined $m / z 69.06\left(\mathrm{C}_{5} \mathrm{H}_{9}^{+}\right.$, potentially dehydrated pentanal $)$and found that $m / z 69.06$ showed a different temporal profile (as discussed below), suggesting that the signals at $m / z 73.06$ and 87.07 may arise from butanone and pentanone, respectively.

The two masses at $m / z 73.02$ and 87.04 suggest the molecular ions $\mathrm{C}_{3} \mathrm{H}_{4} \mathrm{O}_{2}^{+}$and $\mathrm{C}_{4} \mathrm{H}_{6} \mathrm{O}_{2}^{+}$, respectively. As discussed in Sect. 3.2 the signal at $m / z 73.02$ observed in Type 1 and 2 experiments on the reaction of ozone with LA was attributed to MDA. The sequential masses at $m / z 73.02$ and 87.04 are hence attributed to $\mathrm{C} 3$ and $\mathrm{C} 4$ dicarbonyls, respectively.

Figure $10 \mathrm{~b}$ presents the second set of products which were only observed in the ozone reaction with the coastal sample, SML-CA. Different from the first set of products, these signals increased quickly upon ozone exposure then dropped back to background levels and did not rise with a second ozone exposure. This behavior suggests they arise from lower concentration precursors that are consumed upon the initial ozone exposure. The signals at $m / z$ 57.07, 67.05, 81.07, 69.06 and 83.08, correspond to $\mathrm{C}_{4} \mathrm{H}_{9}^{+}, \mathrm{C}_{5} \mathrm{H}_{7}^{+}, \mathrm{C}_{6} \mathrm{H}_{9}^{+}$, $\mathrm{C}_{5} \mathrm{H}_{9}^{+}$and $\mathrm{C}_{6} \mathrm{H}_{11}^{+}$, respectively, and except for $m / z$ 57.07 


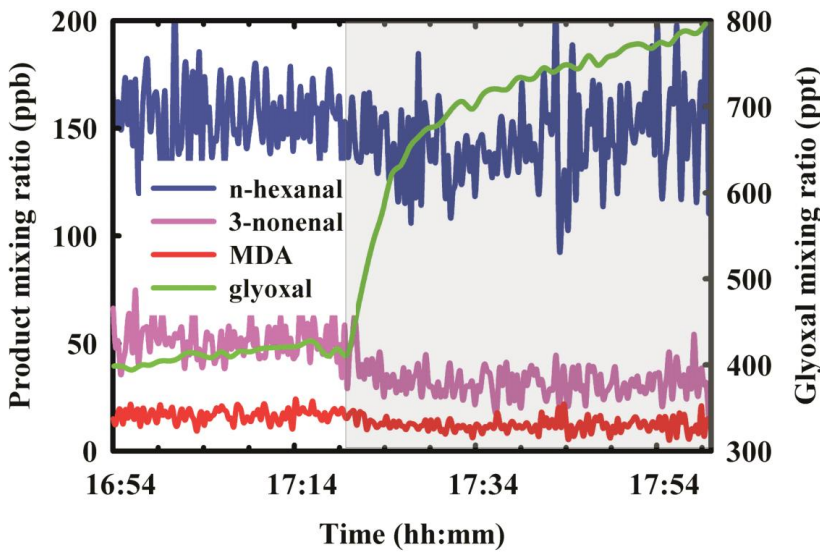

Fig. 9. Flow tube results when a UV lamp is turned on (in the shaded region) to form $\mathrm{OH}$ in a second flow tube in series downstream of the LA oxidation flow tube.
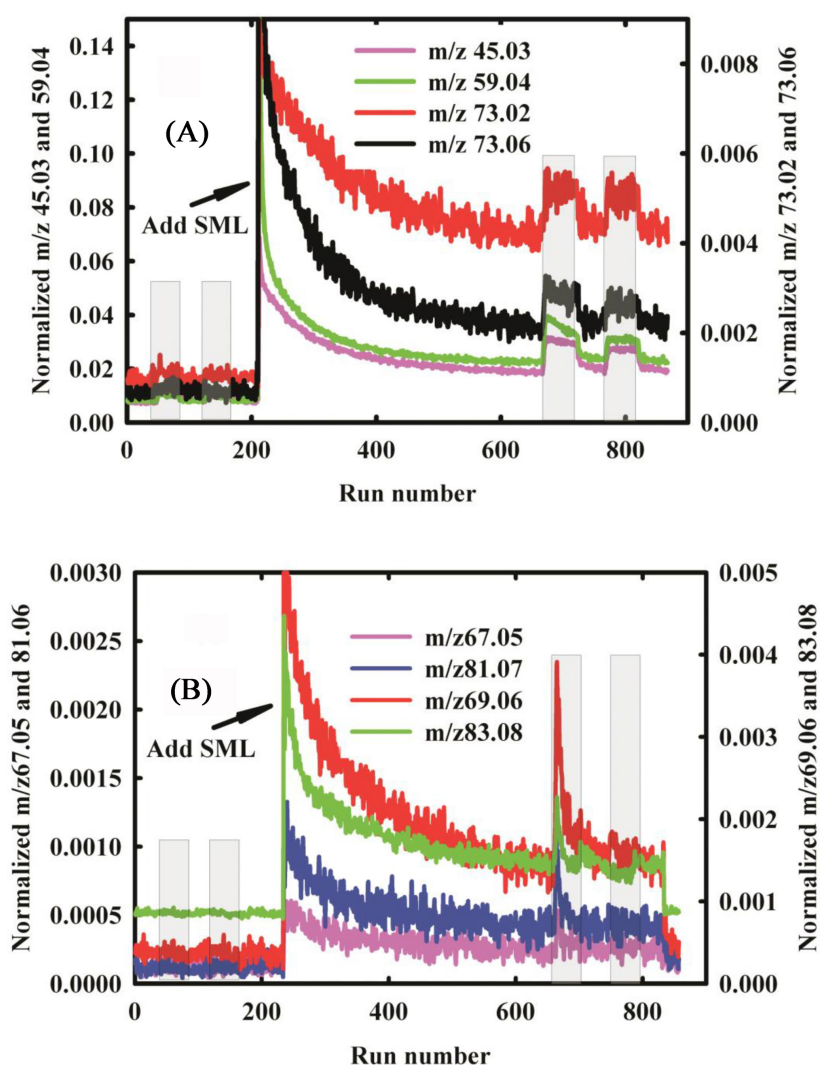

Fig. 10. Evolution of selected masses during oxidation of SML-CA with ozone. The shaded areas represent when ozone was present at $350 \mathrm{ppb}$.

these signals also appear in the oxidation of LA (Fig. 2), where they were attributed to fragmentation of protonated and/or dehydrated $n$-hexanal and 3-nonenal. The second set of products, therefore, may also originate from similar monocarbonyls, although other precursors cannot be ruled out.
A few other signals also rose in the presence of $\mathrm{O}_{3}$, such as $\mathrm{m} / \mathrm{z}, 65.02$ and 101.02. They match $\mathrm{C}_{2} \mathrm{H}_{3} \mathrm{~F}_{2}^{+}$and $\mathrm{C}_{2} \mathrm{H}_{4} \mathrm{~F}_{3} \mathrm{O}^{+}$, respectively, which are most probably from the Teflon tubing used in the experiments. Meanwhile, additional strong signals, such as $m / z 81.02$ and 85.03 , were steady in the presence and absence of $\mathrm{O}_{3}$.

The PTR-TOF-MS responses to several aldehydes and ketones, namely acetaldehyde, acrolein, acetone and butanone, were found to have similar calibration factors. Using an average calibration factor, the mixing ratios that arise upon ozone exposure of the gas-phase carbonyls from ozonolysis of SML are estimated. For the first set of products, they were $\sim 200$ ppt for C2 and C3 monocarbonyls and $\sim 30 \mathrm{ppt}$ for the $\mathrm{C} 4$ and $\mathrm{C} 5$ monocarbonyls and $\mathrm{C} 3$ and $\mathrm{C} 4$ dicarbonyls. For the second set of products, the maximum monocarbonyl mixing ratios were estimated to be $30-90 \mathrm{ppt}$.

It should be noted that no dicarbonyls were calibrated with the PTR-TOF-MS, so the application of the calibration factor obtained from monocarbonyls may induce high uncertainties in the dicarbonyl quantification. Moreover, even for the structurally similar carbonyls the calibration factors for different isomers can be significantly different (Warneke et al., 2003). Thus, the mixing ratios for the carbonyl products given above should be viewed as only initial estimates.

\section{Conclusions and atmospheric implications}

There are three main conclusions from this work. First, it has been demonstrated that volatile carbonyls, such as $n$-hexanal and 3-nonenal, are formed when LA exists as a monolayer on artificial seawater and is exposed to $\mathrm{O}_{3}$. These species are formed promptly and in high yields. With similar PUFA being common components of the SML, it is likely that exposure of the SML to ozone in the environment will lead to the release of similar volatile aldehydes. To our knowledge this is the first study of the oxidation of a PUFA existing as a monolayer on seawater. This adds to an extensive body of literature which demonstrates that such species are formed when pure unsaturated fatty acids are oxidized (Moise and Rudich, 2002; Thornberry and Abbatt, 2004; Vesna et al., 2009). As well, formation of small VOCs from heterogeneous oxidation of other types of unsaturated organics, such as ozone reaction with vinyl terminated selfassembled monolayers (Dubowski et al., 2004), squalene film (Petrick and Dubowski, 2009) and fumaric acid aerosols (Najera et al., 2010), has also been reported. The only comparable system that has been studied at the air-water interface is the unsaturated phospholipid oxidation, studied by Wadia et al. (2000), where nonanal formation was observed in high yield.

Second, we have demonstrated that highly reactive gasphase dicarbonyls, i.e. malondialdehyde and glyoxal, are formed in the PUFA reaction system, probably through secondary reactions of primary products. These mechanisms 
were confirmed by a chamber study on the gas-phase reaction of 3-hexenal with ozone (Fig. 7) and by further oxidation of primary products from ozonolysis of LA with $\mathrm{OH}$ radicals (Fig. 9). While glyoxal has been measured in the atmosphere (Sinreich et al., 2010), detection of MDA has not been reported. We note that in the biochemical literature, MDA is an important cross-linking agent that reacts with amino groups of enzymes, proteins and DNA (Tappel, 1980; Wang et al., 2009; Passagne et al., 2012). Based on the thiobarbituric acid (TBA) reactive assay (Wang et al., 2009; Passagne et al., 2012), a number of studies suggest that MDA is formed from oxidation of lipid as well as PUFA (Pryor et al., 1976; Frankel, 1984; Scislowski et al., 2005; Santos-Zago et al., 2007). At this point, we are unable to accurately quantify the yields of glyoxal and MDA given that they may be dissolving to some degree in the aqueous sub-phase. The yields reported in the paper are likely lower limits.

Our third conclusion is that ozone exposure to natural SML samples leads to the formation of a wide variety of oxygenated VOCs similar to those formed from PUFA oxidation, i.e. small mono- and dicarbonyls. While it is clear that SML materials are highly complex so that we cannot attribute these products to specific reactants, it is nevertheless important to demonstrate that the SML represents a reactive medium that may lead to VOC production via heterogeneous oxidation. This initial study warrants further investigations of SML-ozone interactions.

\section{Supplementary material related to this article is available online at http://www.atmos-chem-phys.net/14/ 1371/2014/acp-14-1371-2014-supplement.pdf.}

Acknowledgements. S. Zhou would like to thank Jamie Donaldson for helpful discussion about the LA experiments, and Shawna Gao, Jenny Wong and Ran Zhao for assistance with the PTRMS and calibrations. S. Bureekul, H. Furutani, and M. Uematsu would like to thank all crews on R/V Hakuho-Maru for their kind assistance in collecting SML samples. Funding for this work was provided by NSERC. R. Volkamer acknowledges US National Science Foundation for funding under CAREER award NSF-ATM 0847793, and the TORERO project award NSF-AGS 1104104.

Edited by: T. Bartels-Rausch

\section{References}

André, M., Brinis, A., Dallot, S., Gondry, G., Saliot, A., and Lebaron, P.: Field study of the chemical characterization of the upper ocean surface using various samplers, Limnol. Oceanogr.Meth., 2, 374-386, 2004.

Barger, W. R. and Garrett, W. D.: Surface active organic material in the marine atmosphere, J. Geophys. Res., 75, 4561, doi:10.1029/JC075i024p04561, 1970.

Barger, W. R. and Garrett, W. D.: Surface-active organic material in air over the Mediterranean and over the eastern equatorial $\mathrm{Pa}-$ cific, J. Geophys. Res., 81, 3151, doi:10.1029/JC081i018p03151, 1976.

Blanchard, D. C.: Sea-to-air transport of surface active material, Science, 146, 396-397, 1964.

Blaženka, G., Marta, P., Božena, C., and Alain, S.: Organic matter characterization in the sea surface microlayers in the subarctic Norwegian fjords region, Mar. Chem., 105, 1-14, 2007.

Bogumil, K., Orphal, J., Homann, T., Voigt, S., Spietz, P., Fleischmann, O. C., Vogel, A., Hartmann, M., Kromminga, H., Bovensmann, H., Frerick, J., and Burrows, J. P.: Measurements of molecular absorption spectra with the SCIAMACHY preflight model: instrument characterization and reference data for atmospheric remote-sensing in the $230-2380 \mathrm{~nm}$ region, J. Photoch. Photobiol. A, 157, 167-184, 2003.

Brown, R. S., Tse, A., Nakashima, T., and Haddon, R. C.: Symmetries of hydrogen-bonded enol forms of diketones as determined by X-ray photoelectron spectroscopy, J. Am. Chem. Soc., 101, 3157-3162, 1979.

de Gouw, J. A. and Warneke, C.: Measurements of volatile organic compounds in the Earth's atmosphere using proton-transferreaction mass spectrometry, Mass Spectrom. Rev., 26, 223-257, 2007.

Derieux, S., Fillaux, J., and Saliot, A.: Lipid class and fatty acid distributions in particulate and dissolved fractions in the north Adriatic Sea, Org. Geochem., 29, 1609-1621, 1998.

Dibble, T. S.: Intramolecular hydrogen bonding and double H-atom transfer in peroxy and alkoxy radicals from isoprene, J. Phys. Chem. A, 108, 2199-2207, 2004a.

Dibble, T. S.: Prompt chemistry of alkenoxy radical products of the double $\mathrm{H}$-atom transfer of alkoxy radicals from isoprene, J. Phys. Chem. A, 108, 2208-2215, 2004b.

Donaldson, D. J. and George, C.: Sea-surface chemistry and its impact on the marine boundary layer, Environ. Sci. Technol., 46, 10385-10389, 2012.

Donaldson, D. J. and Vaida, V.: The influence of organic films at the air-aqueous boundary on atmospheric processes, Chem. Rev., 106, 1445-1461, 2006.

Dubowski, Y., Vieceli, J., Tobias, D. J., Gomez, A., Lin, A., Nizlorodov, S. A., McIntire, T. M., and Finlayson-Pitts, B. J.: Interaction of gas-phase ozone at $296 \mathrm{~K}$ with unsaturated selfassembled monolayers: a new look at an old system, J. Phys. Chem. A, 108, 10473-10485, 2004.

Dunne, E., Galbally, I. E., Lawson, S., and Patti, A.: Interference in the PTR-MS measurement of acetonitrile at $\mathrm{m} / \mathrm{z}, 42$ in polluted urban air - a study using switchable reagent ion PTR-MS, Int. J. Mass Spectrom., 319-320, 40-47, 2012.

Ellison, G. B., Tuck, A. F., and Vaida, V.: Atmospheric processing of organic aerosols, J. Geophys. Res.-Atmos., 104, 11633, doi:10.1029/1999JD900073, 1999.

Fang, J., Kawamura, K., Ishimura, Y., and Matsumoto, K.: Carbon isotope composition of fatty acids in the marine aerosols from the Western North Pacific: implication for the source and atmospheric transport, Environ. Sci. Technol., 62, 2598-2604, 2002.

Frankel, E. N.: Lipid oxidation: mechanisms, products and biological significance, J. Am. Oil. Chem. Soc., 61, 1908-1917, 1984.

Galloway, M. M., Huisman, A. J., Yee, L. D., Chan, A. W. H., Loza, C. L., Seinfeld, J. H., and Keutsch, F. N.: Yields of oxidized volatile organic compounds during the $\mathrm{OH}$ radical initiated oxidation of isoprene, methyl vinyl ketone, and methacrolein under 
high-NO ${ }_{x}$ conditions, Atmos. Chem. Phys., 11, 10779-10790, doi:10.5194/acp-11-10779-2011, 2011.

Gašparovic, B., Kozarac, Z., Saliot, A., Casovic, B., and Möbius, D.: Physico-chemical characterization of natural and ex-situ reconstructed sea-surface microlayers. J. Colloid Interface Sci., 208, 191-202, 1998.

Gill, P. S., Graedel, T. E., and Weschler, C. J.: Organic films on atmospheric aerosol particles, fog droplets, cloud droplets, raindrops, and snowflakes, Rev. Geophys. Space Geol., 21, 903-920, 1983.

González-Lebrada, E., Schmidt, R., and DeWolf, C. E.: Kinetic analysis of the ozone processing of an unsaturated organic monolayer as a model of an aerosol surface, Phys. Chem. Chem. Phys., 9, 5814-5821, 2007.

Hermans, C., Vandaele, A.C., Carleer, M., Fally, S., Colin, R., Jenouvrier, A., Coquart, B., and Mérienne, M.-F.: Absorption cross-sections of atmospheric constituents: $\mathrm{NO}_{2}, \mathrm{O}_{2}$, and $\mathrm{H}_{2} \mathrm{O}$, Environ. Sci. Pollut. R., 6, 151-158, 1999.

Hung, H.-M. and Ariya, P.: Oxidation of oleic acid and oleic acid/sodium chloride(aq) mixture droplets with ozone: changes of hygroscopicity and role of secondary reactions, J. Phys. Chem. A, 111, 620-632, 2007.

Hung, H.-M., Katrib, Y., and Martin, S. T.: Products and mechanisms of the reaction of oleic acid with ozone and nitrate radical, J. Phys. Chem. A, 109, 4517-4530, 2005.

Ip, H. S. S., Huang, X. H. H., and Yu, J. Z.: Effective Henry's law constants of glyoxal, glyoxalic acid, and glycolic acid, Geophys. Res. Lett., 36, L01802, doi:10.1029/2008GL036212, 2009.

Jordan, A., Haidacher S., Hanel, G., Hartungen, E., Herbig, J., Mark, L., Schottkowsky, R., Seehause, H., Sulzer, P., and Mark, T. D.: An online ultra-high sensitivity proton-transfer reaction mass spectrometer combined with switchable reagent ion capability, Int. J. Mass Spectrom., 2286, 32-38, 2009.

Katrib, Y., Martin, S. T., Hong, H. M., Rudich, Y., Zhang, H., Slowik, J. G., Davidovits, P., Jayne, J. T., and Worsnop, D. R.: Products and mechanisms of ozone reactions with oleic acid for aerosol particles having core-shell morphologies, J. Phys. Chem. A, 108, 6686-6695, 2004.

Kawamura, K. and Gagosian, R. B.: Implications of $\omega$ oxocarboxylic acids in the remote marine atmosphere for photooxidation of unsaturated fatty acids, Nature, 325, 330-332, 1987.

King, M. D., Rennie, A. R., Thompson, K. C., Fisher, F. N., Dong, C. C., Thomas, R. K., Pfrang, C., and Hughes, A. V.: Oxidation of oleic acid at the air-water interface and its potential effects on cloud critical super saturations, Phys. Chem. Chem. Phys., 11, 7699-7707, 2009.

Kozarac, Z., Risovic, D., Frka, S., and Möbius, D.: Reflection of light from the air/water interface covered with sea-surface microlayers, Mar. Chem., 96, 99-111, 2005.

Lambe, A. T., Ahern, A. T., Williams, L. R., Slowik, J. G., Wong, J. P. S., Abbatt, J. P. D., Brune, W. H., Ng, N. L., Wright, J. P., Croasdale, D. R., Worsnop, D. R., Davidovits, P., and Onasch, T. B.: Characterization of aerosol photooxidation flow reactors: heterogeneous oxidation, secondary organic aerosol formation and cloud condensation nuclei activity measurements, Atmos. Meas. Tech., 4, 445-461, doi:10.5194/amt-4-445-2011, 2011.

Marty, J. C., Saliot, A., Buatmenard, P., Chesselet, R., and Hunter, K. A.: Relationship between the lipid compositions of marine aerosols, the sea surface mircolayer, and subsurface water, J. Geophys. Res., 84, 5707, doi:10.1029/JC084iC09p05707, 1979.

McNeil, V. F., Wolfe, G. M., and Thornton, J. A.: The oxidation of oleate in submicron aqueous salt aerosols: evidence of a surface process, J. Phys. Chem. A, 111, 1073-1083, 2007.

Mochida, M., Kitamori, Y., Kawamura, K., Nojiri, Y., and Suzuki, K.: Fatty acids in the marine atmosphere: factors governing their concentrations and evaluation of organic films on sea-salt particles, J. Geophys. Res., 107, 4325, doi:10.1029/2001jd001278, 2002.

Moise, T. and Rudich, Y.: Reactive uptake of ozone by aerosolassociated unsaturated fatty acids: kinetics, mechanism, and products, J. Phys. Chem. A, 106, 6469-6476, 2002.

Myriokefalitakis, S., Vrekoussis, M., Tsigaridis, K., Wittrock, F., Richter, A., Brühl, C., Volkamer, R., Burrows, J. P., and Kanakidou, M.: The influence of natural and anthropogenic secondary sources on the glyoxal global distribution, Atmos. Chem. Phys., 8, 4965-4981, doi:10.5194/acp-8-4965-2008, 2008.

Najera, J. J., Percival, C. J., and Horn, A. B.: Kinetic studies of the heterogeneous oxidation of maleic and fumaric acid aerosols by ozone under conditions of high relative humidity, Phys. Chem. Chem. Phys., 12, 11417-11427, 2010.

Parrish, C. C., Thompson, R. J., and Deibel, D.: Lipid classes and fatty acids in plankton and settling matter during the spring bloom in a cold ocean coastal environment, Mar. Ecol.-Prog. Ser., 286, 57-68, 2005.

Passagne, I., Morille, M., Rousset, M., Pujalté, I., and L'Azou, B.: Implication of oxidative stress in size-dependent toxicity of silica nanoparticles in kidney cells, Toxicology, 299, 112-124, 2012.

Paulot, F., Crounse, J. D., Kjaergaard, H. G., Kuerten, A., St Clair, J. M., Seinfeld, J. H., and Wennberg, P. O.: Unexpected epoxide formation in the gas-phase photooxidation of isoprene, Science, 325, 730-733, 2009.

Petrick, L. and Dubowski, Y.: Heterogeneous oxidation of squalene film by ozone under various indoor conditions, Indoor Air, 19, 381-391, 2009.

Pogorzelski, S. J. and Kogut, A. D.: Structural and thermodynamic signatures of marine microlayer surfactant films, J. Sea Res., 49, 347-356, 2003.

Pryor, W. A., Stanley, J. P., and Blair, E.: Autoxidation of polyunsaturated fatty acids: II. A suggested mechanism for the formation of TBA-reactive materials from prostaglandin-like endoperoxides, Lipids, 11, 370-379, 1976.

Rouvière, A. and Ammann, M.: The effect of fatty acid surfactants on the uptake of ozone to aqueous halogenide particles, Atmos. Chem. Phys., 10, 11489-11500, doi:10.5194/acp-1011489-2010, 2010.

Saiz-Lopez, A. and von Glasow, R.: Reactive halogen chemistry in the troposphere., Chem. Soc. Rev. 41, 6448-6472, 2012.

Santos-Zago, L. F., Botelho, A. P., and Oliveira, A. C.: Supplementation with commercial mixtures of conjugated linoleic acid in association with vitamin $\mathrm{E}$ and the process of lipid autoxidation in rates, Lipids, 42, 845-854, 2007.

Scislowski, V., Bauchart, D., Gruffat, D., Laplaud, P., and Durand, D.: Effect of dietary $n-6$ and $n-3$ polyunsaturated fatty acids on peroxidizability of lipoprotein in steers, Lipids, 40, 1245-1256, 2005. 
Sinreich, R., Coburn, S., Dix, B. and Volkarmer, R.: Ship-based detection of glyoxal over the remote tropical Pacific Ocean, Atmos. Chem. Phys. 10, 11359-11371, 2010.

Tappel, A. L.: Measurement of and protection from in vivo lipid peroxidation, in: Free Radicalsin Biology, vol. IV, edited by: Pryor, W. A., Academic Press, New York, 2-43, 1980.

Thalman, R. and Volkamer, R.: Inherent calibration of a blue LED-CE-DOAS instrument to measure iodine oxide, glyoxal, methyl glyoxal, nitrogen dioxide, water vapour and aerosol extinction in open cavity mode, Atmos. Meas. Tech., 3, 1797-1814, doi:10.5194/amt-3-1797-2010, 2010.

Thornberry, T. and Abbatt, J. P. D.: Heterogeneous reaction of ozone with liquid unsaturated fatty acids: detailed kinetics and gasphase product studies, Phys. Chem, Chem. Phys., 6, 84-93, 2004.

Trivella, A., Coussan, S., and Chiavassa, T.: Malondialdehyde synthesis, Synthetic. Commun., 38, 3285-3290, 2008.

Vandaele, A. C., Hermans, C., Fally, S., Carleer, M., Colin, R., Mérienne, M. F., Jenouvrier, A., and Coquart, B.: Highresolution Fourier transform measurement of the $\mathrm{NO}_{2}$ visible and near infrared absorption cross-section: temperature and pressure effects, J. Geophys. Res., 107, ACH 3-1, doi:10.1029/2001JD000971, 2002.

Vesna, O., Sax, M., Kalberer, M., Gaschen, A., and Ammann, M.: Product study of oleic acid ozonolysis as function of humidity, Atmos. Environ., 43, 3662-3669, 2009.

Volkamer, R., Spietz, P., Burrows, J., and Platt, U.: High-resolution absorption cross-section of glyoxal in the UV-sis and IR spectral ranges, J. Photoch. Photobio. A, 172, 35-46, 2005 a.

Volkamer, R., Barnes, I., Platt, U., Molina, L. T., and Molina, M. J.: Remote s ensing of glyoxal by differential optical absorption spectroscopy (DOAS): advancements in simulations champers and field experiments, Paper presented a Advanced Research Workshop on Environmental Simulation Chambers: Application to Atmospheric Chemical Processes, NATO, Zakopane, Poland, 1-4 October, $2005 b$.
Voss, L.F., Bazerbashi, M. F., Beekman, C. P., Hadad, C. M., and Allen, H. C.: Oxidation of oleic acid at air/liquid interfaces, J. Geophys. Res., 112, D06209, doi:10.1029/2006JD007677, 2007.

Wadia, Y., Tobias, D. J., Stafford, R., and Finlayson-Pitts, B. J.: Real-time monitoring of the kinetics and gas-phase products of the reaction of ozone with an unsaturated phospholipid at the airwater interface, Langmuir, 16, 9321-9330, 2000.

Wang, F., Gao, F., Lan, M., Yuan, H., Huang, Y., Liu, J.: Oxidative stress contributes to silica nanoparticle-induced cytotoxicity in human embryonic kidney cells, Toxicol. In Vitro, 23, 808-815, 2009

Warneke, C., De Gouw, J. A., Kuster, W. C., Goldan, P. D., and Fall, R.: Validation of atmospheric VOC measurements by proton-transfer-reaction mass spectrometry using a gaschromatographic preseparation method, Environ. Sci. Technol., 37, 2494-2501, 2003.

Washenfelder, R. A., Langford, A. O., Fuchs, H., and Brown, S. S.: Measurement of glyoxal using an incoherent broadband cavity enhanced absorption spectrometer, Atmos. Chem. Phys., 8, 7779-7793, doi:10.5194/acp-8-7779-2008, 2008.

Wilson, W. B. and Collier, A.: The production of surface-active materials by marine phytoplankton cultures, J. Mar. Res., 30, 15-26, 1972.

Zahardis, J. and Petrucci, G. A.: The oleic acid-ozone heterogeneous reaction system: products, kinetics, secondary chemistry, and atmospheric implications of a model system - a review, Atmos. Chem. Phys., 7, 1237-1274, doi:10.5194/acp-7-1237-2007, 2007.

Zhao, Z., Husainy, S., Stoudemayer, C. T., and Smith, G. D.: Reactive uptake of $\mathrm{NO}_{3}$ radicals by unsaturated fatty acid particles, Phys. Chem. Chem. Phys., 13, 17809-17817, 2011.

Ziemann, P. J.: Aerosol products, mechanisms, and kinetics of heterogeneous reactions of ozone with oleic acid in pure and mixed particles, Faraday Discuss., 130, 469-490, 2005. 